\title{
Competitive Climate and Workaholism: Negative Sides of Future Orientation and Calling
}

\author{
Anita C. Keller ${ }^{1}$, Daniel Spurk ${ }^{2}$, Franziska Baumeler ${ }^{2}$, Andreas Hirschi $^{2}$ \\ ${ }^{1}$ Michigan State University, Department of Psychology, United States \\ ${ }^{2}$ University of Bern, Department of Psychology, Switzerland
}

Author Note

Requests for reprints should be addressed to Anita Keller, Department of Psychology, 315 Psychology Building, Michigan State University, East Lansing, MI 48824; e-mail: keller97@msu.edu

\section{Acknowledgement}

The research reported in this article was supported by a grant from the Swiss National Science Foundation (P2BEPI_158962). The funding sources had no involvement in analysis and interpretation of data, in the writing of the report, or in the decision to submit the article for publication. 


\begin{abstract}
The perception of a competitive climate at work creates stress, uncertainty, and a desire to outperform colleagues. In this study, we investigated whether a competitive climate is associated with increased workaholism. Furthermore, we assumed that especially employees with a future orientation and a presence of a calling will show more workaholic behaviour when a competitive climate is present. Hierarchical regression analyses among 812 employees in Germany confirmed our hypotheses: Competitive climate was positively related with workaholism and was stronger related to workaholism under conditions of high future orientation and high calling. These findings suggest that contextual factors at work and individual factors interact to form workaholism. Our results may be explained by the experience of more uncertainty in competitive work climates for individuals with high future orientation and the presence of a calling. Consequently, these employees may invest more physical and cognitive efforts into their work to cope with the competition. Keywords: competitive climate, workaholism, future orientation, calling
\end{abstract}




\section{Competitive Climate and Workaholism: Negative Sides of Future Orientation and Calling}

\section{Introduction}

The changing labor market (e.g., global competition) has forced many employees to put more effort into their work (van Beek, Hu, Schaufeli, Taris, \& Schreurs, 2012). This type of heavy investment can be associated with workaholism, which is a tendency to work excessively hard and to be obsessed with work, which manifests itself in working compulsively (Schaufeli, Taris, \& Bakker, 2008). A recent meta-analysis showed that workaholism has positive (e.g., better career prospects) and negative (e.g., higher counterproductive work behavior) relations with work outcomes. However, the relationships with family and individual non-work outcomes are clearly negative, and workaholism appears to be harmful for physical and mental health. The meta-analysis also showed that dispositions and aspects of the work environment can act as reinforcements to workaholism (Clark, Michel, Zhdanova, Pui, \& Baltes, 2014). From a theoretical understanding, organizational values and climate, and particularly peer competition, could support the development of workaholism as well (Liang \& Chu, 2009; $\mathrm{Ng}$, Sorensen, \& Feldman, 2007). With this study, we extend knowledge on antecedents of workaholism by investigating the contextual variable of competitive climate as a source of workaholism. This provides more knowledge regarding the still understudied role of organizational factors for the inducement of workaholism. Additionally, we investigate the possibility that employees with a future orientation and a calling are more prone to become workaholics when confronted with competitive climates, thereby providing a more fine-grained understanding of the conditions under which competitive climates and workaholism are related. 


\subsection{Workaholism: Definition and Antecedents}

Workaholism has been described as a need to work compulsively and excessively. Working compulsively refers to an individual's inner drive to work and feeling compelled to work. When not working, feelings of guilt and discomfort occur (Schaufeli, Taris, \& Bakker, 2008; Spence \& Robbins, 1992). Working excessively can be described as working extremely hard over and above the degree that is expected by the employer or set by the employment contract. There are no specific assumptions regarding the motivation to do so (Schaufeli, Taris, \& Bakker, 2008).

Conceptually, models regarding the inducement of workaholism (e.g., Liang \& Chu, 2009; Ng et al., 2007) include personal factors (e.g., personality, self-esteem, and work values), sociocultural and work-family factors (e.g., learning experiences in childhood, conflicts at home, and the economic situation), and work or organizational factors (e.g., competition at work, career systems, and stressors). Taken together, the models assume that workaholism is related to multiple personal and contextual variables that facilitate or reduce workaholism.

Most of the empirical research on precursors of workaholism analyzed dispositional variables (e.g., Big Five and negative affectivity) or work-related variables (e.g., job demands and work involvement) as antecedents of workaholism. However, within this set of analyzed correlates, contextual-organizational factors such as competitive climate have not been investigated - although they may play an important role for the inducement of workaholism.

\subsection{Competitive Psychological Climate and Workaholism}

Competitive psychological climate is defined "as the degree to which employees perceive organizational rewards to be contingent on comparisons of their performance" with their coworkers (Brown, Cron, \& Slocum, 1998, p. 89). Competition usually is either 
considered as having positive or negative effects. Some researchers see competition as positive because individuals inherently want to compete with each other (cf. social comparison theory; Festinger, 1954), and competition can increase motivation and focuses attention on the task which results in higher performance (Fletcher, Major, \& Davis, 2008). However, a study that tested the assumption of better performance at an individual level found that performance was not affected by competitive climates (Brown et al., 1998). Others see competition as possibly harmful and unhealthy because competition leads to negative behaviors such as undermining others or exploitation of oneself (Kohn, 1992). In competitive climates, employees may perform at high levels but still not succeed in terms of organizational rewards (i.e., salary and managerial status) (Clark et al., 2014). This perception of possible losses while investing much time and effort can lead to feelings of uncertainty and stress (Fletcher et al., 2008). As a result, employees who perceive a competitive climate may invest greater efforts to be superior to colleagues and start feeling discomfort and guilt when not working (Schaufeli, Taris, \& Bakker, 2008). In accordance with these arguments, competitive climates have the potential to foster behaviors that are linked with workaholism.

Hypothesis 1: Competitive climate is positively associated with workaholism.

\subsection{Future Orientation as Moderator between Competitive Climate and}

\section{Workaholism}

The first moderator we investigated in our study was future orientation, also called future focus. Future orientation is an individual characteristic that describes the ability to envision future events and states (Szpunar, Watson, \& McDermott, 2007) or one's preference for allocation of attention to the future (Shipp, Edwards, \& Lambert, 2009). Future oriented cognition has been associated with long-term planning and career adaptability, which are beneficial for employees (e.g., career planning) and organizations 
(e.g., strategic planning) (Das, 1987; Zacher, 2014). Among other factors, future orientation has been shown to be an important driver of longer strategic planning horizons and achievements (Fried \& Slowik, 2004). The positive relations with achievements may be based on the proneness of future oriented individuals to anticipate what is next; this enables these individuals to proactively shape their employment circumstances and careers (Zacher, 2014).

Future oriented cognition can be activated through environmental conditions such as organizational climate (Strobel, Tumasjan, Sporrle, \& Welpe, 2013). As described above, competitive climates can create uncertainty and anticipation of wins or losses (Fletcher et al., 2008). Gains and losses are valued differently in anticipation than in retrospect. Positive and negative emotional reactions towards future events tend to be more extreme than towards past events (Caruso, Gilbert, \& Wilson, 2008). Therefore, the anticipation of a possible future loss, a scenario that is induced through a competitive climate, may be experienced more frequently and as more threatening to individuals with a future orientation. One strategy to deal with this discomfort is through behavior that could make winning more likely, for example, working longer and harder. To cope with the uncertainty associated with a competitive climate, future oriented employees may also engage more often in strategic planning in an attempt to find new methods to outshine others and to advance themselves over their team members, resulting in constantly thinking of work.

Hypothesis 2: The relationship between competitive climate and workaholism is stronger for individuals with a high future orientation. 


\subsection{Presence of Calling as a Moderator between Competitive Climate and}

\section{Workaholism}

As a second moderator, we investigated the presence of a calling. Research has shown that having a calling is commonly associated with positive work and well-being outcomes such as increased work engagement, job satisfaction, and life satisfaction (Duffy \& Dik, 2013). However, recent research also noted the possibility that the positive effects of a calling may depend on being able to live out the calling (Duffy, Bott, Allan, Torrey, \& Dik, 2012). Moreover, having a calling may have negative effects, such as dissatisfaction or distress, when the calling remains unanswered (Berg, Grant, \& Johnson, 2010). People with a calling should be strongly motivated to be able to actually live their calling because only lived callings promise positive effects such as job and life satisfaction (Duffy et al., 2012; Duffy \& Dik, 2013), whereas unanswered callings can be a source of distress (Berg et al., 2010). People who are already able to live out their calling to a considerable degree should therefore be motivated to maintain the jobs, positions, and tasks that allow them to continue living their calling. Similarly, individuals who are not or barely able to live their calling should be motivated to obtain the jobs, positions, and tasks that allow them to live their calling. For both types of people with a calling, a competitive climate is likely perceived as a threat to their ability to be able to (continue) living their calling because a competitive climate implies that desired jobs, positions, and tasks are more difficult to obtain or maintain and, thus, again creates uncertainty. Hence, similar to future-oriented people, employees with a calling may start to feel the need to constantly work and work longer and harder to be able to obtain or maintain the jobs, positions, and tasks that allow them to be able to live their calling. Therefore, we assume that people with a calling may show increased tendencies to work compulsively and excessively if they are working in a competitive climate. 
Hypothesis 3: The relationship between competitive climate and workaholism is stronger for individuals with a high presence of calling.

\section{Methods}

\subsection{Participants and Procedure}

Data collection occurred at the end of 2014, and participants were recruited via a German online panel service. The sampling goal was to recruit employed adults in the age groups of 25 to 34 and 50 to 59 years that were representative for German employees in private business in terms of gender and education. A random selection $(N=3,307)$ of members of the online panel were invited to participate in the survey, and 1,805 (54.58\%) clicked on the invitation link and expressed consent to participate. Of those respondents, 965 met the criteria regarding gender and education, worked at least 20 hours per week, and were employed in private industry (not self-employed or in education). 880 respondents completed more than $50 \%$ of the questionnaires and provided no inconsistent or atypical responses that could have indicated minimal interest and insufficient seriousness. After excluding 68 participants because of missing values on study variables, the final sample included 812 employees ( $45 \%$ female). The mean age in the first age group (25 to 34$)$ was 30.14 years $(S D=2.78)$ and in the second age group (50 to 59) was 53.81 years $(S D=2.75)$. Participants worked from 18 to 70 hours per week with a mean of 40.87 hours per week $(S D=7.97)$ in the last six months. Participants worked for the same organization from one month up to 42 years, with a mean of 9.15 years $(S D=9.37)$.

\subsection{Measures}

Competitive psychological climate. Four items were used to measure competitive psychological climate (Brown et al., 1998; Fletcher et al., 2008), scoring on a seven-point scale from 1 (strongly disagree) to 7 (strongly agree). To translate the scale (e.g., "My 
manager frequently compares my performance with that of my coworkers") from English to German we followed conventional back translation procedures.

Workaholism. Workaholism was measured with the German version of the Dutch Work Addiction Scale (DUWAS; Schaufeli, Taris, \& Bakker, 2008). Five items assessed working compulsively (e.g., "I feel that there's something inside me that drives me to work hard"), and five items assessed working excessively (e.g., "I find myself continuing to work after my co-workers have called it quits"). Participants answered the ten items ranging from 1 (not at all true) to 6 (totally true).

Future Orientation. The four items measuring future orientation by Shipp et al. (2009), e.g., "I think about what my future has in store", were translated into German and back translated into English by the authors. Participants answered how often these actions occurred from 1 (never) to 7 (constantly).

Calling. The German version (Hirschi, 2011) of the Brief Calling Scale (BCS; Dik, Eldridge, Steger, \& Duffy, 2012) assessed the presence of calling. The two items (e.g., "I have a calling to a particular kind of work") were answered on a five-point scale ranging from 1 (not at all true of me) to 5 (totally true of me).

Control variables. We used gender, age group, and working hours as control variables in our study. Previous studies suggested that gender and age is related to competitive climates (Fletcher et al., 2008; Niederle \& Vesterlund, 2011) and workaholism (Mazzetti, Schaufeli, \& Guglielmi, 2014; Schaufeli, Taris, \& Bakker, 2008). In addition, research showed that older employees may have higher coping resources to deal with work stressors (Shirom, Shechter Gilboa, Fried, \& Cooper, 2008) and therefore, may be less affected by competitive climates. We included our second control variable, working hours, for two reasons. First, not all participants of our sample worked full-time, and one could assume that competitive climates are less relevant for workaholism among 
part-time employees. Second, workaholism emphasizes the negative experience associated with working (e.g., feeling compelled to work) and not working (e.g., feeling guilty when not working) and should have effects that go beyond working long hours (Schaufeli, Taris, \& van Rhenen, 2008).

\section{Results}

\subsection{Preliminary Analyses}

First, we calculated confirmatory factor analyses (CFA) to determine that the analyzed concepts are empirically distinct. Therefore, we tested a model in which all assumed constructs (i.e., competitive psychological climate, presence of calling, future orientation, and workaholism) represent single correlated factors $\left(\chi^{2}=589.93, d f=160\right.$, $\mathrm{CFI}=.95, \mathrm{RMSEA}=.05, \mathrm{SRMR}=.06)$. We compared this model against two alternative models (comparison model 1: predictor and moderators represent one factor and workaholism represents one factor, comparison model 2: a one-factor model in which all items represent one single factor). According to a chi-square difference test, both comparison models revealed worse model fit compared to the theoretical model (all $p s<.001)$. Therefore, we concluded that the used measures can be used for hypotheses testing and that common method variance is not a major issue because the one-factor model revealed worse model fit (i.e., Harman's single factor test, cf. Podsakoff, MacKenzie, \& Podsakoff, 2012). Second, means, standard deviations, correlations, and Cronbach alpha of the study variables are shown in Table 1 . The central study variables of competitive climate, future orientation, presence of calling, and workaholism related positively to each other ( $r$ s from .10 to .32 , all $p$-values $<.01$ ).

\subsection{Hypotheses Testing}

Hierarchical regression analyses were applied to test our hypotheses. After standardizing all continuous independent variables (Aiken \& West, 1991), we entered the 
control variables gender, age group and work hours in the first step, followed by the main effects of competitive climate, future orientation, and presence of calling (step two), and the interaction terms of competitive climate with future orientation and presence of calling (step three). We also conducted a bootstrap analysis and report the bias-corrected $90 \%$ confidence intervals of all effects within the regression analysis. Table 2 shows the findings of the hierarchical regression analysis predicting workaholism.

Results of the first step of the regression analysis revealed a positive relation of working hours $(\beta=.24, p<.001)$ and a negative relation of age $(\beta=-.17, p<.001)$ with workaholism. Gender was not significantly related to workaholism $(\beta=-.06, n s)$. Note that inclusion or exclusion of gender did not change regression results.

Confirming Hypothesis 1, we found a positive relation of competitive climate with workaholism $(\beta=.25, p<.001)$ meaning that individuals who worked in competitive climates also worked more excessively and compulsively (Table 2, step 2). We also found a positive relationship of future orientation with workaholism $(\beta=.19, p<.001)$, but presence of calling was not significantly related to workaholism $(\beta=-.01, n s)$. Step two explained an additional $12 \%$ of the variance in workaholism.

Lastly, we found significant interaction effects of competitive climate with future orientation $(\beta=.07, p<.05)$ and with presence of calling $(\beta=.08, p<.05)$ on workaholism, explaining an additional $1 \%$ of variance in workaholism. $90 \%$ confidence intervals did not include zero for both interaction effects. However, for the interaction between competitive climate and presence of calling, zero was included in the $95 \%$ interval (results available from authors). Figure 1 (future orientation) and Figure 2 (presence of calling) show a graphic representation of these interactions. In accordance with the procedure recommended by Aiken and West (1991), the relationship between competitive climate and workaholism was plotted at different levels of future orientation 
and presence of calling (i.e., one standard deviation above and below the mean). The findings revealed that workaholism was highest for employees who worked in a competitive climate and were (a) oriented towards their future and (b) experienced high levels of calling. Additional simple slope tests showed that competitive climate was positively related with workaholism under conditions of high future orientation (for $S D+1: \beta=.23, t=7.15, p<.001)$ and less positively related with workaholism under conditions of low future orientation (for $S D-1: \beta=.14, t=4.36, p<.001$ ). Furthermore, competitive climate was positively related with workaholism under conditions of high presence of calling (for $S D+1: \beta=.24, t=7.32, p<.001$ ) and less positively related with workaholism under conditions of low presence of calling (for $S D-1: \beta=.13, t=4.02, p<$ .001). Therefore, our hypotheses that the competitive climate-workaholism relation is stronger under conditions of high future orientation (Hypothesis 2) and high presence of calling (Hypothesis 3) were supported.

\section{Discussion}

The results reported in this study suggest that employees who perceived a work environment characterized by frequent performance comparisons with others and recognition being dependent on one's performance also reported higher levels of workaholism. This finding advances empirical research and theoretical models of antecedents of workaholism (e.g., Liang \& Chu, 2009) and implies that, in addition to aspects of employees (e.g., personality and values), the perceived competitiveness of the work environment may also be related to workaholism. In a competitive climate, employees may feel encouraged or forced to outshine their colleagues. Work behaviors such as working on multiple tasks at once and working longer than one's colleagues may lead to better performance compared to one's colleagues. As such, workaholism is a likely reaction to a competitive climate within the organization. 
Our study also showed that this relationship was stronger among employees with a future orientation and a calling. The fact that future orientation had a moderating function contributes to the emerging field of studies on the role of future orientation in the workplace. Research suggested that the ability to envision future events is beneficial in work environments and in the pursuit of one's career (Fried \& Slowik, 2004; Zacher, 2014). Our results extend these findings and suggest that, under competitive conditions, the tendency to anticipate future events and possibilities may foster feelings of stress and uncertainty. A strategy to deal with these feelings may be to invest more resources to meet the performance standards and outperform colleagues in the workplace. Currently, we can only speculate whether the workaholic behavior reduces the experience of uncertainty and fear and therefore is maintained. It is also possible that competitive climates are rewarding individuals with a future orientation because the climate triggers behavior that can make them more successful. Because future oriented individuals tend to invest more in their work, these individuals may also be more successful in the workplace and be rewarded with recognition, more responsibilities, bonuses, and promotions. Nevertheless, workaholism also includes the inner drive to work and feelings of discomfort if one is not working. Therefore, success may come at a price for them.

The moderating effect of calling may occur for similar reasons. Additionally, employees who have a calling tend to be strongly committed to their career (Duffy et al., 2012) and work to maintain or fulfill their calling. Competitive climates pose a threat to being able to live one's calling. Therefore, competitive climates may foster feelings of guilt and discomfort when not working and lead to working harder among employees with a calling. Extending previous studies which mainly focused on positive effects (Duffy \& Dik, 2013), our results showed a potential dark side of callings. Future theoretical developments on calling may include the possibility that working conditions that create 
threats to the fulfillment of one's calling may foster unhealthy behavior among employees with a calling. This result as well as the moderating function of future orientation imply that personal characteristics that generally lead to favorable outcomes can also foster unhealthy and counterproductive behaviors and experiences in certain organizational environments.

In addition, the results revealed that future orientation is positively related to workaholism. Hence, it appears that individuals who focus on future actions and events are more prone to workaholism. Future research may explore if these individuals simultaneously show other personality characteristics that are positively related to workaholism, for example, conscientiousness (Clark et al., 2014; Shipp et al., 2009). Lastly, the presence of calling was positively related to workaholism on a bivariate level. Therefore, it may be that individuals with strong work-related identities are more prone to workaholism. This finding is in accordance with a study by $\mathrm{Ng}$ and colleagues (2008) who showed that occupational identity was a positive predictor for working long hours, which is related to workaholism.

\subsection{Limitations}

A limitation of our study is the cross-sectional design. Because it is possible that employees who tend to show workaholic behaviors also perceive their work environment as competitive, a longitudinal study may reveal whether workaholism affects competitive climates, whether competitive climates affect workaholism, or whether they affect each other reciprocally over time. The moderating effects we found in this study are relatively small but may become stronger over time. Another possible limitation of our study is the age gap in the sampling procedure. Therefore, the findings should not be generalized to all age groups and career stages. However, we also tested if the regression coefficients 
would differ between the two age groups but did not find any significant differences. Nonetheless, future studies should conduct similar studies including middle age groups.

\subsection{Conclusion}

Our study showed that the organizational aspect of competitive climate was associated with workaholism, thereby indicating that in addition to personality, values, and job characteristics, organizational factors may act as a reinforcement to workaholism. Organizations may pay attention to set performance standards but also value other criteria such as helping colleagues and performing tasks that are not directly related to fulfilling performance goals. It also appears important to monitor individuals who perceive a calling and tend to anticipate future events because, for these individuals, competitive environments may be particularly threatening, which may lead to unhealthy behaviors. 


\section{References}

Aiken, L. S., \& West, S. G. (1991). Multiple regression: Testing and interpreting interactions. Newbury Park, CA: Sage Publications.

Berg, J. M., Grant, A. M., \& Johnson, V. (2010). When callings are calling: Crafting work and leisure in pursuit of unanswered occupational callings. Organization Science, 21, 973-994.

Brown, S. P., Cron, W. L., \& Slocum, J. W. (1998). Effects of trait competitiveness and perceived intraorganizational competition on salesperson goal setting and performance. The Journal of Marketing, 62, 88-98.

Caruso, E. M., Gilbert, D. T., \& Wilson, T. D. (2008). A wrinkle in time asymmetric valuation of past and future events. Psychological Science, 19, 796-801.

Clark, M. A., Michel, J. S., Zhdanova, L., Pui, S. Y., \& Baltes, B. B. (2014). All work and no play? A meta-analytic examination of the correlates and outcomes of workaholism. Journal of Management, 1-38.

Das, T. K. (1987). Strategic planning and individual temporal orientation. Strategic Management Journal, 8, 203-209.

Dik, B. J., Eldridge, B. M., Steger, M. F., \& Duffy, R. D. (2012). Development and validation of the calling and vocation questionnaire (CVQ) and brief calling scale (BCS). Journal of Career Assessment, 20, 242-263.

Duffy, R. D., Bott, E. M., Allan, B. A., Torrey, C. L., \& Dik, B. J. (2012). Perceiving a calling, living a calling, and job satisfaction: testing a moderated, multiple mediator model. Journal of Counseling Psychology, 59, 50-59.

Duffy, R. D., \& Dik, B. J. (2013). Research on calling: What have we learned and where are we going? Journal of Vocational Behavior, 83, 428-436. 
Festinger, L. (1954). A theory of social comparison processes. Human Relations, 7, 117140.

Fletcher, T. D., Major, D. A., \& Davis, D. D. (2008). The interactive relationship of competitive climate and trait competitiveness with workplace attitudes, stress, and performance. Journal of Organizational Behavior, 29, 899-922.

Fried, Y., \& Slowik, L. H. (2004). Enriching goal-setting theory with time: An integrated approach. Academy of Management Review, 29, 404-422.

Hirschi, A. (2011). Callings in career: A typological approach to essential and optional components. Journal of Vocational Behavior, 79, 60-73.

Kohn, A. (1992). No contest: The case against competition. New York: Houghton Mifflin Harcourt.

Liang, Y.-W., \& Chu, C.-M. (2009). Personality traits and personal and organizational inducements: Antecedents of workaholism. Social Behavior and Personality: An International Journal, 37, 645-660.

Mazzetti, G., Schaufeli, W. B., \& Guglielmi, D. (2014). Are workaholics born or made? Relations of workaholism with person characteristics and overwork climate. International Journal of Stress Management, 21, 227-254.

Ng, T. W. H., \& Feldman, D. C. (2008). Long work hours: A social identity perspective on meta-analysis data. Journal of Organizational Behavior, 29, 853-880.

Ng, T. W. H., Sorensen, K. L., \& Feldman, D. C. (2007). Dimensions, antecedents, and consequences of workaholism: a conceptual integration and extension. Journal of Organizational Behavior, 28, 111-136.

Niederle, M., \& Vesterlund, L. (2011). Gender and competition. Annual Review of Economics, 3, 601-630. 
Podsakoff, P. M., MacKenzie, S. B., \& Podsakoff, N. P. (2012). Sources of method bias in social science research and recommendations on how to control it. Annual Review of Psychology, 63, 539-569.

Schaufeli, W. B., Taris, T. W., \& Bakker, A. B. (2008). It takes two to tango. Workaholism is working excessively and working compulsively. In R. J. Burke \& C. L. Cooper (Eds.), The long work hours culture. Causes, consequences and choices (pp. 203-226). Bingley: Emerald.

Schaufeli, W. B., Taris, T. W., \& van Rhenen, W. (2008). Workaholism, Burnout, and Work Engagement: Three of a Kind or Three Different Kinds of Employee Wellbeing? Applied Psychology: An International Review, 57, 173-203.

Shipp, A. J., Edwards, J. R., \& Lambert, L. S. (2009). Conceptualization and measurement of temporal focus: The subjective experience of the past, present, and future. Organizational Behavior and Human Decision Processes, 110, 1-22.

Shirom, A., Shechter Gilboa, S., Fried, Y., \& Cooper, C. L. (2008). Gender, age and tenure as moderators of work-related stressors' relationships with job performance: A meta-analysis. Human Relations, 61, 1371-1398.

Spence, J. T., \& Robbins, A. S. (1992). Workaholism: Definition, measurement, and preliminary results. Journal of Personality Assessment, 58, 160-178.

Strobel, M., Tumasjan, A., Sporrle, M., \& Welpe, I. M. (2013). The future starts today, not tomorrow: How future focus promotes organizational citizenship behaviors. Human Relations, 66, 829-856.

Szpunar, K. K., Watson, J. M., \& McDermott, K. B. (2007). Neural substrates of envisioning the future. Proceedings of the National Academy of Sciences, 104, 642-647. 
van Beek, I., Hu, Q., Schaufeli, W. B., Taris, T. W., \& Schreurs, B. H. J. (2012). For fun, love, or money: What drives workaholic, engaged, and burned-out employees at work? Applied Psychology: An International Review, 61, 30-55.

Zacher, H. (2014). Individual difference predictors of change in career adaptability over time. Journal of Vocational Behavior, 84, 188-198. 
COMPETITIVE CLIMATE AND WORKAHOLISM

Table 1

Means, Standard Deviations, and Pearson's Correlations for the Study Variables.

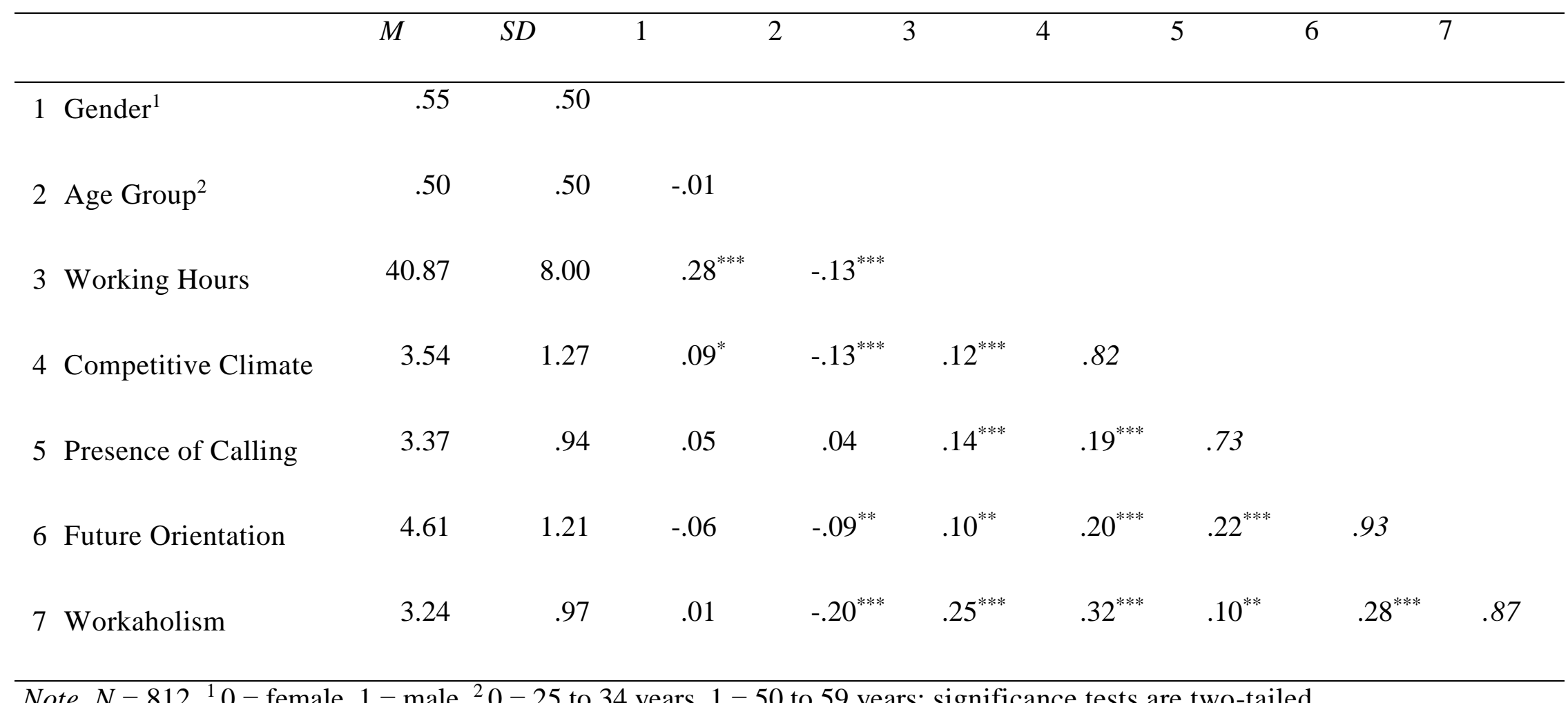

Note. $N=812,{ }^{1} 0=$ female, $1=$ male,${ }^{2} 0=25$ to 34 years, $1=50$ to 59 years; significance tests are two-tailed.

Diagonal shows Cronbach alpha for competitive climate, future orientation, and workaholism, and item correlation

for presence of calling. $* p<.05, * * p<.01, * * * p<.001$. 
Table 2

Regression and Interaction Analyses for Study Variables on Workaholism.

\begin{tabular}{|c|c|c|c|c|c|c|c|c|c|c|c|c|c|c|c|}
\hline & \multicolumn{5}{|c|}{ Step 1} & \multicolumn{5}{|c|}{ Step 2} & \multicolumn{5}{|c|}{ Step 3} \\
\hline & & & LCI & UCI & & & & LCI & UCI & & & & LCI & UCI & \\
\hline & $B$ & $S E B$ & $90 \%$ & $90 \%$ & $\beta$ & $B$ & $S E B$ & $90 \%$ & $90 \%$ & $\beta$ & $B$ & $S E B$ & $90 \%$ & $90 \%$ & $\beta$ \\
\hline Constant & 3.47 & .06 & 3.37 & 3.57 & & 3.43 & .06 & 3.33 & 3.52 & & 3.41 & .06 & 3.32 & 3.52 & \\
\hline Gender $^{1}$ & -.12 & .07 & -.22 & .01 & -.06 & -.11 & .06 & -.22 & .01 & -.06 & -.12 & .06 & -.23 & -.01 & -.06 \\
\hline Age Group ${ }^{2}$ & -.34 & .07 & -.45 & -.22 & $-.17^{* * *}$ & -.25 & .06 & -.36 & -.14 & $-.13^{* * *}$ & -.26 & .06 & -.37 & -.16 & $-.14^{* * *}$ \\
\hline Working Hours & .23 & .03 & .17 & .29 & $.24^{* * *}$ & .19 & .03 & .13 & .24 & $.20^{* * *}$ & .19 & .03 & .13 & .24 & $.20^{* * * *}$ \\
\hline Competitive Climate & & & & & & .25 & .03 & .19 & .31 & $.25^{* * *}$ & .24 & .03 & .19 & .30 & $.25^{* * *}$ \\
\hline Future Orientation & & & & & & .18 & .03 & .13 & .25 & $.19^{* * *}$ & .18 & .03 & .12 & .24 & $.19^{* * *}$ \\
\hline Presence of Calling & & & & & & -.01 & .03 & -.06 & .05 & -.01 & -.01 & .03 & -.06 & .06 & -.01 \\
\hline Competitive Climate $\mathrm{x}$ & & & & & & & & & & & .06 & .03 & .01 & .10 & $.07^{*}$ \\
\hline Future Orientation & & & & & & & & & & & & & & & \\
\hline Competitive Climate $\mathrm{x}$ & & & & & & & & & & & 07 & 03 & 01 & 12 & $\Omega Q^{*}$ \\
\hline Presence of Calling & & & & & & & & & & & & & & & \\
\hline$R^{2}$ & & & & & $.09^{* * * *}$ & & & & & $.21 * * *$ & & & & & $.22 * * *$ \\
\hline$\Delta R^{2}$ & & & & & & & & & & $.12 * * *$ & & & & & $.01 * * *$ \\
\hline
\end{tabular}


$F$ for change in $R^{2}$ $F(3,808)=27.73^{* *}$

$F(6,805)=34.99^{* *}$

$F(8,803)=28.41^{* * *}$

Note. $N=812 .{ }^{1} 0=$ female, $1=$ male,${ }^{2} 0=25$ to 34 years, $1=50$ to 59 years, LCI $=$ lower confidence interval, UCI $=$ upper confidence interval.

${ }^{*} p<.05 .{ }^{* *} p<.01 .{ }^{* * *} p<.001$. 


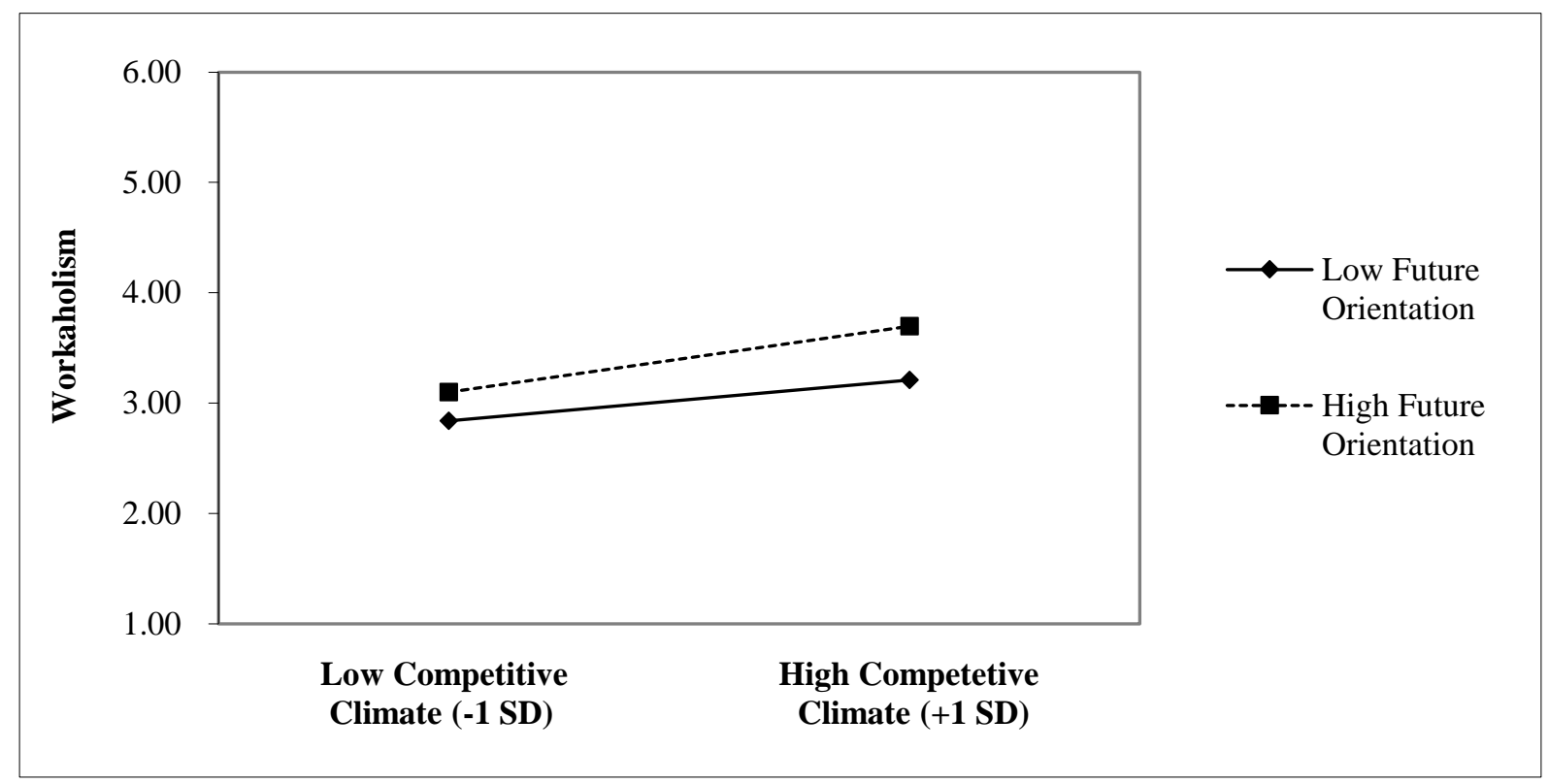

Figure 1. Future orientation as a moderator for the competitive climate-workaholism relationship 




Figure 2. Calling as a moderator for the competitive climate-workaholism relationship 